\title{
RESEARCH
}

Open Access

\section{Hospitalization for acute cerebellitis in children affected by varicella: how much does it cost?}

Elena Bozzola ${ }^{1 *}$ D, Stefano Guolo², Giulia Macchiarulo', Lidia Festa', Giulia Spina', Andrzej Krzysztofiak?', Annalisa Grandin ${ }^{1}$, Mauro Bozzola ${ }^{3}$, Massimiliano Raponi ${ }^{2}$ and Alberto Villani ${ }^{1}$

\begin{abstract}
Background: Chickenpox is a highly contagious airborne disease caused by the varicella zoster virus. It is generally benign and self-limiting, but it may be responsible of life-threatening complications. Acute cerebellitis (AC) is the most common neurological complication and is associated with prolonged hospitalization in the acute phase (HAP).

Aim of the study: To estimate the costs of AC HAP in children affected by varicella.

Materials and methods: We retrospectively reviewed the medical records of a pediatric cohort hospitalized for chickenpox AC over a period of 15 years (from October 2003 to October 2018) and we analyzed acute care costs. For any patient the HAP has been calculated. The final value includes cost of hospital accommodation and management at the Pediatric and Infectious Diseases Unit. To this cost, the price of procedures (imaging, laboratory exams, medical and paramedical evaluations) and medical treatments was added.

Results: In the study period, 856 children had been hospitalized for varicella. Out of them, 65 met a diagnosis of AC and were included in the study. The hospitalization length was of 10 days (range 3-20 days). The median cost of HAP for each patient was of 5366 euro, with an average annual cost of 23,252 €. The most significant part of HAP is due to the cost of hospital accommodation and management at the Pediatric Infectious Diseases Unit, which was about $€ 537.78$ for a single day.
\end{abstract}

Discussion: Although AC post-varicella is rare, its HAP cost is not negligible resulting in substantial economic burden. Vaccination would have probably prevented varicella and AC complication, avoiding hospitalization.

Conclusions: Financial studies are important for evaluate the cost saving in order to influence public funding decisions. Further studies are necessary to investigate the economic burden of the disease.

Keywords: Chickenpox, Cost, Hospitalization, Children

\footnotetext{
* Correspondence: elena.bozzola@opbg.net

${ }^{1}$ Pediatric and Infectious Disease Unit, Bambino Gesù Children Hospital, Rome, Italy

Full list of author information is available at the end of the article
}

(c) The Author(s). 2020 Open Access This article is licensed under a Creative Commons Attribution 4.0 International License, which permits use, sharing, adaptation, distribution and reproduction in any medium or format, as long as you give appropriate credit to the original author(s) and the source, provide a link to the Creative Commons licence, and indicate if changes were made. The images or other third party material in this article are included in the article's Creative Commons licence, unless indicated otherwise in a credit line to the material. If material is not included in the article's Creative Commons licence and your intended use is not permitted by statutory regulation or exceeds the permitted use, you will need to obtain permission directly from the copyright holder. To view a copy of this licence, visit http://creativecommons.org/licenses/by/4.0/. The Creative Commons Public Domain Dedication waiver (http://creativecommons.org/publicdomain/zero/1.0/) applies to the data made available in this article, unless otherwise stated in a credit line to the data. 


\section{Background}

Chickenpox is a highly contagious airborne disease caused by the varicella zoster virus (VZV). Even if it is considered benign and self-limiting, it may be responsible of complications and may require hospitalization [1]. In details, 0.1 to $1.5 \%$ of children affected by varicella are admitted to hospital due to a severe course of varicella [1-4]. Among neurological complications, varicella had been related to post infectious encephalitis, cerebellitis, acute myelitis and stroke or stroke like episodes, meningitis, encephalitis, myelitis and vasculopathy [5]. Acute cerebellitis (AC) is the most common neurological complication of chickenpox as it may represent the $44.7 \%$ of all neurological complications $[5,6]$. Furthermore, it affects $0.05 \%$ of children with chickenpox infection [7]. In childhood, $A C$ is associated with prolonged hospitalization in the acute phase (HAP). To date, vaccination constitutes the best preventive strategies against VZV infections [8].

\section{Aim of the study}

Aim of the study is to estimate the costs of AC-HAP in children affected by varicella.

\section{Materials and methods}

For the purpose of our study, we retrospectively reviewed the medical cards of patients hospitalized at Bambino Gesù Children Hospital, Rome, Italy, for chickenpox from October 2003 to October 2018. Patients over 18 years of age as well as children with immunodeficiency disorders were excluded. According to the literature, the diagnosis of chickenpox was clinical, based on the evidence of typical skin lesions in varying stages of development and resolution [9]. A neurological complication was defined as an unfavorable neurological evolution occurring within 3 weeks of varicella onset [10]. The diagnosis of AC was clinical as well, mainly based on the following findings: ataxia, unsteady gait or fine motor movement, trembling of the head and trunk in an upright position and the extremities when attempting to move against gravity [11]. The medical records of patients with the clinical-confirmed diagnosis. Patients who did not fulfill the inclusion criteria were excluded from the study. As for the others, direct medical costs were extracted from the Lazio Regional Health Service Tariffs. The appropriate procedure codes were applied, in order to evaluate the single cost of any exam and therapy. For any patient the HAP has been calculated. The final value includes cost of hospital accommodation and management at the Pediatric and Infectious Diseases Unit. To this cost, the price of procedures (imaging, laboratory exams, medical and paramedical evaluations) and medical treatments was added. HAP cost of patients with cerebellitis in varicella was compared to HAP cost of patients affected by varicella not complicated by AC. The t-test was used to compare the costs between the two groups.

\section{Results}

We identified 856 children hospitalized for chickenpox. Among them, 181 (21\%) were affected by neurological complications, mainly by AC (65 children, 7.59\%). The mean age of patients affected by AC was of 5.49 years (range from 1.5 to 15.58 years, median 4.75 years). The proportion of male and female was similar $(53.8 \%$ males and $46.2 \%$ female). Any patient had no underlying medical condition. None of the included patients had been previously vaccinated for varicella. The median cost of HAP for each patient was of 5366 euro (range from 1763 to 11,872 euro; mean cost of 6068 euro), higher than the one extracted by ICD-9-CM code from 052.0 to 052.9 (range from 1660 to 1800 euro). Medical condition both at $\mathrm{AC}$ onset and during hospitalization may have complicated the disease, requiring a prolonged length stay, further exams and therapies. We observed a similar trend of the mean HAP cost between patients aged from 1 to 5 years ( 30 patients), 5 to 10 years ( 28 patients) and older than 10 years (3 patients), respectively 6138, 6324 and 6430 euro.

Varicella therapy involves symptomatic care, pain management and medical treatment. For this reason, we evaluated for each patient the cost of laboratory exams (median cost of $€ 180,42$; mean cost of $€ 154,21 €$; range from $€ 0$ to $€ 498,64)$, medical and paramedical examinations (median cost of $€ 45,32$; mean cost of $€ 45,45$; range from $€ 20,66$ to $€ 103,3)$ and therapeutic treatment (median cost of $€ 38$,4; mean cost of $€ 42,42$; range from $€ 15,36$ to $€ 284,81$ ). Drugs, such as antiviral or steroid treatment, contribute to higher HAP. In fact, thirty children (46\%) who required a medical therapy had an HAP cost of 2757 euro higher than those without therapy.

Nevertheless, the most significant part of HAP is represented by the cost of hospital accommodation and management at the Pediatric Infectious Diseases Unit, which is about $€ 537.78$ for a single day. Patients had been hospitalized for a mean time of 10.5 days (range from 3 to 20 days).

We compared the hospitalization cost between the 65 patients affected by varicella AC (Group A) and the other 791 patients admitted to the hospital for varicella but without AC (Group B) and hospitalized for a mean time of 7 days (range from 2 to 19 days).

HAP cost in Group A was higher compared Group B ( $€ 5366$ and $€ 3806$ respectively). In details, we found out a significant higher instrumental cost in Group A than in Group B ( $€ 143,76$ and $€ 65,67$ respectively), correlated to imaging exams. 
Table 1 Comparison of HAP costs between patients affected by $A C$ and those without $A C$

\begin{tabular}{llll}
\hline Parameters (median value) & Patients with AC & Patients without AC & $p$ \\
\hline Total cost $(€)$ & 5366 & 3806 & 0.59 \\
Laboratory cost $(€)$ & 180,42 & 178,22 & 0.06 \\
Instrumental cost $(€)$ & 143,76 & 65,67 & 0.02 \\
Special visits $(€)$ & 45,32 & 42,61 & 0.09 \\
Therapy costs $(€)$ & 38,4 & 28,53 & 0.06 \\
\hline
\end{tabular}

Table 1 summarizes the HAP cost, the price of procedures (imaging, laboratory exams, medical and paramedical evaluations) and medical treatments in Groups A and B (Table 1).

\section{Discussion}

Chickenpox is a childhood vaccine-preventable disease which may require hospitalization and relevant medical care services, representing a financial cost [12].

There is evidence that varicella has a significant economic impact.

We performed a MEDLINE search to estimate the cost of AC HAP, using the keywords (“"Chickenpox"[Mesh]) AND "Chickenpox/complications”[Mesh]) AND ("Chickenpox/economics"[Mesh]). Our review concerned scientific publications in the time period between September 2009-September 2018, referring to patients younger than 18 years of age, without chickenpox but not cerebellar complications 2) if they concerned cerebellitis but not cost analysis 3) if they concerned patients older than 18 years. Our MEDLINE analysis identified 6 reports. Nevertheless, after application of exclusion criteria, none of them remained for review. They were excluded because: concerned costs on vaccine and vaccination programs [1]; concerned cost of chickenpox and of complications but not specifically AC-HAP [4]; reported only clinical data [1]. In literature the HAP for varicella may vary, depending on the study, ranging from 600 dollars to 4583 dollars per person, depending on the study [12-18].

The annual direct cost of varicella-related hospitalization of previously health children was estimated at 11210 dollars in Turkey and of 116,287 euro in Spain [12, 19]. Considering both inpatients and outpatients, an estimated annual cost of varicella may be even higher, accounting from $€$ 187,5 million per year to $23,954,617$ CAD $[1,20]$.

Neurological complications had been associated with high HAP of 6612 dollars. As well as in our study, the day cost of hospitalization contributed to more than $97 \%$ to the total cost of HAP [20]. We found that the median cost of varicella AC HAP was of 5366 euro, with an average annual cost of $23,252 €$. To the best of our knowledge, no scientific studies on the economic burden of AC-HAP had been previously performed. A limitation of our study is the absence of evaluation of societal costs, the so called indirect costs, attributable to ACHAP in children affected by varicella. The indirect costs, such as work and productivity loss incurred by parents caring for their children, and instructed medical and paramedical assistance, certainly account for an important part of the global costs.

Post marketing surveillance in the USA have consistently shown nearly $100 \%$ protection against moderate to severe varicella disease [21]. A scenario of no varicella vaccination compared to different scenarios with vaccination at 13 months of age evidenced an overall cost saving by a highly effective vaccine coverage [22]. In our study, none of the patients had been previously vaccinated for varicella, even if they were all eligible for vaccination (the youngest patient was 1.5 years old). Vaccination would have probably prevented varicella and its AC complication, avoiding vaccination in Italian children born from 1st January 2017. It is expected a reduction of the incidence of varicella and cases requiring hospitalizations: this could be cost-effective reducing hospital and medical care resources within a few years following higher vaccination rates. In particular, considering other Countries experience, mandatory vaccination programs are related to higher coverage rates and reductions in varicella-associated costs [23, 24]. Further studies could be performed to analyze these aspects in our population within a few years. Simulation analysis on societal and health costs revealed net costs saving with programs for routine varicella vaccination directed at children [25]. In details, a saving of 5.40 dollars for every dollar spent on routine vaccination of preschool children have been demonstrated [26]. Finally, a two-dose routine varicella vaccination of infants is estimated to reduce the costs-both direct and indirect- by $64 \%$ [27].

\section{Conclusions}

Our study provides information regarding the financial burden of AC HAP in otherwise healthy children affected by varicella. AC complication may cause a long hospital stay and consequently a high direct sanitary cost. In the absence of published cost-of-illness reports investigating the burden of $\mathrm{AC}$ varicella in children, our results contribute to extend the knowledge on the economic impact of varicella disease. Hospital costs are an important end-point in health economic evaluation of the diseases and may be used by policy-maker decisors to implement vaccination programs.

Of note, no patient included in the study had received at least one dose of varicella vaccine. Prevention of varicella through vaccination is a priority to avoid the significant burden of its incidence and complications and should be encouraged from a both medical and economic viewpoint. 


\section{Abbreviations}

VZV: Varicella zoster virus; AC: Acute cerebellitis; HAP: Hospitalization in the acute phase

\section{Acknowledgements}

Not applicable.

\section{Authors' contributions}

BE planned the study, MG, SG and FL collected the data, GS and RM performed the economic evaluation of the costs, KA performed the statistical analysis, VA and GA analyzed the literature, BM was a major contributor in writing the manuscript study. All authors read and approved the final manuscript.

\section{Funding}

No Funding

\section{Availability of data and materials}

Availability of data and material at Bambino Gesù Children Hospital, Dr. Bozzola's repository.

\section{Ethics approval and consent to participate}

Not applicable, not sought.

\section{Consent for publication}

Not applicable.

\section{Competing interests}

No Competing interests.

\section{Author details}

'Pediatric and Infectious Disease Unit, Bambino Gesù Children Hospital, Rome, Italy. ${ }^{2}$ Medical Direction, Bambino Gesù Children Hospital, Rome, Italy. ${ }^{3}$ University of Pavia, Pavia, Italy.

Received: 4 March 2020 Accepted: 27 July 2020

Published online: 06 August 2020

\section{References}

1. Banz K, Wagenpfeil S, Neiss A, Hammerschmidt T, Wutzler P. The burden of varicella in Germany. Potential risks and economic impact. Eur J Health Econ. 2004:5(1):46-53.

2. Choo PW, Donahue JG, Manson JE, Platt R. The epidemiology of varicella and its complications. J Infect Dis. 1995;172:706-12.

3. National Committee on Immunization. Statement on recommended use of varicella virus vaccine. Can Commun Dis Rep. 1999;25:1-16.

4. Boelle PY, Hanslik T. Varicella in non-immune persons: incidence, hospitalization and mortality rates. Epidemiol Infect. 2002;129:599-606.

5. Bozzola E, Tozzi AE, Bozzola M, Krzysztofiak A, Valentini D, Grandin A, Villani A. Neurological complications of varicella in childhood: case series and a systematic review of the literature. Vaccine. 2012;30(39):5785-90.

6. Bozzola E, Bozzola M, Tozzi AE, Calcaterra V, Longo D, Krzystofiak A, Villani A. Acute cerebellitis in varicella: a ten year case series and systematic review of the literature. Ital J Pediatr. 2014:19:40-57.

7. Mitoma H, Manto M, Hampe CS. Immune-mediated cerebellar ataxias: practical guidelines and therapeutic challenges. Curr Neuropharmacol. 2019; 17(1):33-58

8. Melegaro A, Marziano V, Del Fava E, Poletti P, Tirani M, Rizzo C, Merler S. The impact of demographic changes, exogenous boosting and new vaccination policies on varicella and herpes zoster in Italy: a modelling and costeffectiveness study. BMC Med. 2018;16:117.

9. American Academy of Pediatrics Committee on Infectious Diseases Prevention of varicella. Recommendations for use of varicella vaccines in children, including a recommendation for a routine 2-dose varicella immunization schedule. Pediatrics. 2007:120(1):221-31.

10. Peterson CL, Mascola L, Chao SM, Lieberman JM, Arcinue EL, Blumberg DA, et al. Children hospitalized for varicella: a prevaccine review. J Pediatr. 1996; 129(4):529-36.

11. Ryan MM, Engle EC. Acute ataxia in childhood. J Child Neurol. 2003;18:30916.
12. Ozdemir H, Candir MO, Karbuz A, Belet N, Tapisiz A, Ciftçi E, Ince E. Chickenpox complications, incidence and financial burden in previously healthy children and those with an underlying disease in Ankara in the prevaccination period. Turk J Pediatr. 2011;53(6):614-25.

13. Giglio N, Monsanto H, Rampakakis E, Yang HK, Kuter BJ, Wolfson LJ. Economic burden of varicella in children 1-12 years of age in Argentina, 2009-2014. J Med Econ. 2018;21(4):416-24

14. Carapetis JR, Russell DM, Curtis N. The burden and cost of hospitalised varicella and zoster in Australian children. Vaccine. 2004:23(6):755-61.

15. Abarca K, Hirsch T, Potin M, Perret C, Zamorano J, González C, Vial P. Complications in children with varicella in 4 hospitals in Santiago, Chile: clinical spectrum and estimation of direct costs. Rev Med Chil. 2001;129(4): 397-404.

16. Sáez-Llorens X, De Suman O, De Morós D, Rubio MP. Complications and costs associated with chickenpox in immunocompetent children. Rev Panam Salud Publica. 2002;12(2):111-6.

17. Lo Presti C, Curti C, Montana M, Bornet C, Vanelle P. Chickenpox: an update. Med Mal Infect. 2019:49:1-8.

18. Markham MH, Darville T. Morbidity and cost of vaccine-preventable varicella in previously healthy children in Arkansas. J Ark Med Soc. 1999:96(7):260-2.

19. Piqueras Arenas Al, Otero Reigada MC, Pérez-Tamarit D, Asensi Botet F, Diosdado Ortín N, Santos DM. Hospitalizations for varicella in the Hospital Infantil La Fe, Valencia, Spain, 2001-2004. An Pediatr (Barc). 2005;63(2):120-4

20. Law B, Fitzsimon C, Ford-Jones L, McCormick J, Riviere M. Cost of chickenpox in Canada: part II. Cost of complicated cases and total economic impact. The immunization monitoring Progra-active (IMPACT). Pediatrics. 1999;104(1 Pt 1):7-14.

21. Kuter BJ, Brown ML, Hartzel J, Williams WR, EvesiKaren A, Black S, et al. Safety and immunogenicity of a combination measles, mumps, rubella and varicella vaccine (ProQuad). Hum Vaccin. 2006;2(5):205-14.

22. Graham J, Wolfson LJ, Kyle J, Bolde-Villarreal CP, Guarneros-DeRegil DB, Monsanto $\mathrm{H}$, et al. Budget impact analysis of multiple varicella vaccination strategies: a Mexico perspective. Hum Vaccin Immunother. 2019. https://doi. org/10.1080/21645515.2019.1672491.

23. Quian J, Rüttimann R, Romero C, Dall'Orso P, Cerisola A, Breuer T, et al. Impact of universal varicella vaccination on 1-year-olds in Uruguay: 19972005. Arch Dis Child. 2008:93(10):845-50.

24. Paternina-Caicedo A, De la Hoz-Restrepo F, Gamboa-Garay O, CastañedaOrjuela C, Velandia-González M, Alvis-Guzmán N. How cost effective is universal varicella vaccination in developing countries? A case-study from Colombia. Vaccine. 2013;31(2):402-9.

25. Skull SA, Wang EE. Varicella vaccination--a critical review of the evidence. Arch Dis Child. 2001;85(2):83-90.

26. Lieu TA, Cochi SL, Black SB, Halloran ME, Shinefield HR, Holmes SJ, et al. Cost-effectiveness of a routine varicella vaccination program for US children. JAMA. 1994:271(5):375-81.

27. Banz K, Iseli A, Aebi C, Brunner M, Schmutz AM, Heininger U. Economic evaluation of varicella vaccination in Swiss children and adolescents. Hum Vacci. 2009;5(12):847-85.

\section{Publisher's Note}

Springer Nature remains neutral with regard to jurisdictional claims in published maps and institutional affiliations.

Ready to submit your research? Choose BMC and benefit from:

- fast, convenient online submission

- thorough peer review by experienced researchers in your field

- rapid publication on acceptance

- support for research data, including large and complex data types

- gold Open Access which fosters wider collaboration and increased citations

- maximum visibility for your research: over $100 \mathrm{M}$ website views per year

At $\mathrm{BMC}$, research is always in progress.

Learn more biomedcentral.com/submission 